\title{
Rupture uterus following blunt trauma at 16 weeks gestation
}

\author{
Jasmeen Kaur*, Bharti Goel, Alka Sehgal
}

Department of Obstetrics \& Gynecology, Government Medical College and Hospital, Sector 32, Chandigarh, India

Received: 3 December 2012

Accepted: 14 December 2012

*Correspondence:

Dr. Jasmeen Kaur,

E-mail: drjasmeen81@yahoo.in

\begin{abstract}
Uterine rupture in pregnancy is a rare and often catastrophic complication with a high incidence of fetal and maternal morbidity. Uterine dehiscence and rupture uterus are more commonly seen in patients with scarred uterus but it is of a rare occurrence in patients with unscarred uterus. We are presenting mid trimester rupture of an unscarred uterus.
\end{abstract}

Keywords: Uterine rupture, Unscarred uterus, Blunt trauma

\section{INTRODUCTION}

Uterine rupture in pregnancy is a rare and often catastrophic complication with a high incidence of fetal and maternal morbidity. Uterine dehiscence and rupture uterus are more commonly seen in patients with scarred uterus but it is of a rare occurrence in patients with unscarred uterus. We are presenting mid trimester rupture of an unscarred uterus.

\section{CASE REPORT}

A 24 year old unbooked unsupervised $\mathrm{G}_{2} \mathrm{P}_{1} \mathrm{~L}_{1}$ presented at $16^{+6}$ weeks pregnancy with history of fall 3 days back and c/o pain lower abdomen and moderate amount of bleeding $\mathrm{p} / \mathrm{v}$ for 2 days, along with history of fainting attacks, no history of any other injury or urinary complaints. She had previous one normal vaginal delivery one and half years back, no history of abortions/ instrumentation or any surgery.

On admission her general condition was poor; she was pale with PR 120/min, BP 80/40 mmHg, RR 26/min and afebrile. Abdomen was slightly distended; tenderness + , 14-16 weeks gravid uterus was palpable. Bleeding P/V was present. On vaginal examination os was closed. Routine investigations, $\mathrm{x}$ ray and ultrasound abdomen was done. Hemoglobin was $7.5 \mathrm{gm} \%$, coagulogram was within normal range. On transabdominal ultrasound minimal free fluid was seen in the peritoneal cavity.
Uterine cavity appeared to be empty and deviated to the right side. Fetus with absent cardiac activity was seen lying outside the uterus on the left side surrounded with blood clots.

On emergency laparotomy there was no haemoperitoneum. Left broad ligament was distended with blood clots and fetus. On opening the broad ligament, fetus and foul smelling blood clots approximately $200 \mathrm{gms}$ were removed. A long lateral wall tears extending from fundus up to internal os with partial avulsion of cervix from uterus was seen. It was repaired and patency of cervical canal and cavity was checked. Bilateral tubal ligation was done, post operatively patient developed wound infection in spite of broad spectrum antibiotic cover.

\section{DISCUSSION}

Rupture uterus is defined as a full-thickness separation of the myometrium and the overlying serosa. Uterine rupture during pregnancy is a rare occurrence that frequently results in life-threatening maternal and fetal compromise. Meta-analysis of pooled data from 20 studies from 1976-2009 indicated an overall incidence of pregnancy-related uterine rupture of 1 per 1,536 pregnancies $(0.07 \%)$. When the studies were limited to a subset of 8 that provided data about the spontaneous rupture of unscarred uteri in developed countries, the rate was 1 per 8,434 pregnancies $(0.012 \%) .{ }^{1-3}$ No cases of uterine rupture occurred among 21,998 primigravidas, 
and only $2(0.0051 \%)$ occurred among 39,529 multigravidas with no uterine scar. ${ }^{4}$ This rate of spontaneous uterine rupture has not changed appreciably over last 40 years, and most of these events occur at term and during labor. Mid trimester uterine rupture is rare. ${ }^{5}$

An 8-fold increased incidence of uterine rupture of 1 in $920(0.11 \%)$ has been noted in developing countries which has been attributed to a higher incidence of neglected and obstructed labor due to inadequate access to medical care.

Rupture uterus in unscarred uterus is usually found in multiparity, misuse of uterotonic drugs, congenital malformations of uterus, obstructed labor, malpresentation, breech extraction, instrumentation and blunt trauma abdomen. Blunt trauma results in uterine rupture in less than one per cent of severe cases. Rupture is more common in a scarred uterus and that too on a direct impact of substantive force. ${ }^{6}$ Approximately $75 \%$ of cases of traumatic uterine rupture involve the uterine fundus.

The signs and symptoms of uterine rupture largely depend on the timing, site, and extent of the uterine defect. Uterine rupture at the site of a previous uterine scar is typically less violent and less dramatic than a spontaneous or traumatic rupture because of their relatively reduced vascularity.

Maternal effects range from severe blood loss, hypovolemic shock, bladder injury, need for hysterectomy and ultimately maternal death and if proper supportive measures are available to treat the mother, the time for definitive surgical intervention before the onset of major maternal morbidity and mortality may often be substantially longer than that for the fetus. Several studies have shown that delivery of the fetus within 10-37 minutes of uterine rupture is necessary to prevent serious fetal morbidity and mortality, ${ }^{7-11}$ which range from fetal hypoxia, fetal acidosis, requirement of admission to a neonatal intensive care unit and neonatal death.

The consequences of uterine rupture during pregnancy depend on the time that elapses from the rupture until institution of definitive therapy. Definitive therapy for the fetus is delivery and for mother they are supportive and resuscitative until surgical intervention can be undertaken to arrest the often life-threatening uterine hemorrhage. Uterine bleeding is typically most profuse when the uterine tear is longitudinal rather than transverse. Conservative surgical management involving uterine repair with or without tubal ligation followed by repeat caesarean in next pregnancy at 36 weeks of gestation ${ }^{12,13}$ should be reserved for women who have the following findings:
a. Good general condition
b. Desire for future childbearing
c. Easily controllable uterine hemorrhage

d. Low transverse uterine rupture

e. No extension of the tear to the broad ligament, cervix, or paracolpos

f. No clinical or laboratory evidence of an evolving coagulopathy

Hysterectomy should be considered the treatment of choice when intractable uterine bleeding occurs or when the uterine rupture sites are multiple, longitudinal, or low lying.

\section{CONCLUSION}

Prompt diagnosis and treatment which includes fluid resuscitation and blood transfusion, definitive surgical intervention and adequate antimicrobial therapy is the key in management of rupture uterus.

\section{REFERENCES}

1. Rageth JC, Juzi C, Grossenbacher H. Delivery after previous cesarean: a risk evaluation. Swiss Working Group of Obstetric and Gynecologic Institutions. Obstet Gynecol 1999;93:332-7.

2. Miller DA, Goodwin TM, Gherman RB, Paul RH. Intrapartum rupture of the unscarred uterus. Obstet Gynecol 1997;89(5 pt 1):671-3.

3. Sweeten KM, Graves WK, Athanassiou A. Spontaneous rupture of the unscarred uterus. Am J Obstet Gynecol 1995;172:1851-6.

4. Golan A, Sandbank O, Rubin A. Rupture of the pregnant uterus. Obstet Gynecol 1980;56:549-54.

5. Khakarwal S, Agarwal M. Spontaneous uterine rupture at 20 weeks gestation. J Obstet Gynecol India 2009;59:246-8.

6. ACOG educational bulletin. Postpartum hemorrhage. Number 243, January 1998 (replaces No. 143, July 1990). American College of Obstetricians and Gynecologists. Int J Gynaecol Obstet 1998;61:79-86.

7. Bujold E, Bujold C, Hamilton EF, et al. The impact of a single-layer or double-layer closure on uterine rupture. Am J Obstet Gynecol 2002;186:1326-30.

8. Rodriguez MH, Masaki DI, Phelan JP, Diaz FG. Uterine rupture: are intrauterine pressure catheters useful in the diagnosis? Am J Obstet Gynecol 1989;161:666-9.

9. Johnson C, Oriol N. The role of epidural anesthesia in trial of labor. Reg Anesth 1990;15:304-8.

10. Kieser KE, Baskett TF. A 10-year population-based study of uterine rupture. Obstet Gynecol 2002;100:749-53.

11. Bujold E, Blackwell SC, Gauthier RJ. Cervical ripening with transcervical foley catheter and the risk of uterine rupture. Obstet Gynecol 2004;103:18-23.

12. Bashir A. Maternal mortality in Faisalabad city-A longitudinal study. The Gynaecologist 1993;3:1420. 
13. Lim AC, Kwee A, Bruinse HW. Pregnancy after uterine rupture: a report of 5 cases and review of the literature. Obstet Gynecol Surv 2005;60:613-7.

DOI: $10.5455 / 2320-1770 . \mathrm{ijr} \operatorname{cog} 001612$

Cite this article as: Kaur J, Goel B, Sehgal A.

Rupture uterus following blunt trauma at 16 weeks gestation. Int J Reprod Contracept Obstet Gynecol 2012;1:64-6. 